\title{
Auroral Ionospheric Ion Feeding of the Inner Plasma Sheet during Substorms
}

\author{
Ioannis A. DAGLIS ${ }^{1,2}$, W. Ian AXFOrD ${ }^{1}$, Stefano Livi' ${ }^{1}$, Berend WILKEN ${ }^{1}$, \\ Manuel Grande ${ }^{3}$, and Finn SøraAs ${ }^{4}$ \\ ${ }^{1}$ Max-Planck-Institut für Aeronomie, Katlenburg-Lindau, Germany \\ ${ }^{2}$ Permanent address: Institute of Space Research, National Observatory of Athens, Greece \\ ${ }^{3}$ Rutherford Appleton Laboratory, Chilton, England \\ ${ }^{4}$ Department of Physics, University of Bergen, Bergen, Norway
}

(Received September 20, 1995; Revised January 16, 1996; Accepted February 15, 1996)

\begin{abstract}
During the last decade, satellite observations in the nightside magnetosphere have confirmed the presence of energetic $(>20 \mathrm{keV})$ ionospheric-origin ions in the near-Earth magnetotail. Observations also imply that the feeding of the equatorial magnetosphere with ions from the high-latitude ionosphere can be very fast and intense at times. In the present paper we use observations from the Combined Release and Radiation Effects Satellite (CRRES) to investigate the characteristics of ion energy density variations. Multispecies studies of the energy density give important clues on the coupling of the different plasma sources and their participation in the substorm energization. The measurements, coming from the Magnetospheric Ion Composition Spectrometer (MICS), confirm previous results obtained from the AMPTE/CCE-CHEM spectrometer, with regard to the timing of the high-latitude ionosphere response to the equatorial magnetosphere disturbances. The energy density profile of the ionospheric-origin $\mathrm{O}^{+}$follows the intensity enhancements of the westward electrojet very closely in time, exhibiting a continuing increase, contrary to the behaviour of the other major ion species $\mathrm{H}^{+}$and $\mathrm{He}^{++}$. This feature, which is consistent with statistical studies of AMPTE/CCE observations, points towards a fast activation of an extraction/acceleration mechanism which feeds the inner plasma sheet with ions of ionospheric origin during the substorm expansion.
\end{abstract}

\section{Introduction}

Measurements by mass/charge-discriminating energetic plasma instruments on board several spacecraft in the late 1970s (e.g., Balsiger et al., 1980) and the 1980s (e.g., Gloeckler and Hamilton, 1987) confirmed the early observations of $\mathrm{O}^{+}$ions by Shelley et al. (1972). Observations from both equatorial and polar orbiting spacecraft (e.g. Hultqvist, 1991) have demonstrated that the high-latitude terrestrial ionosphere is a significant hot plasma source for the magnetosphere. The two most important ionospheric outflow regions are the auroral region and the dayside cleft; statistical studies by Yau et al. (1984) and Lockwood et al. (1985) concluded that the auroral ionosphere is the major source of magnetospheric $\mathrm{O}^{+}$ions.

Statistical studies of AMPTE/CCE observations in the nightside magnetosphere during substorms (Daglis et al., 1991, 1992, 1994a) have shown that the energy density of the ionosphericorigin $\mathrm{O}^{+}$ions correlates strongly with the auroral electrojet intensity. This is a feature of the $\mathrm{O}^{+}$ions only; the $\mathrm{He}^{++}$ions (of solar wind origin) show a very poor correlation with the auroral electrojet intensity. The trend of $\mathrm{O}^{+}$is presented in Fig. 1 and is indicative of a fast extraction/acceleration mechanism closely related to the energy dissipation at the nightside auroral ionosphere. The parameters that appear on top of Fig. 1 refer to the fit applied to the original data. The regression coefficient is equal to $b=2.3 \cdot 10^{-3}$, so that we have $E D\left(O^{+}\right)=-0.04+2.3 \cdot 10^{-3} \cdot A L$, where $A L$ is given in $\mathrm{nT}$ and $E D$ in $\mathrm{keV} / \mathrm{cm}^{3}$. The correlation coefficient is $r=0.73$, with an $F$-ratio value of 143.26 , which (for 126 observations) yields 


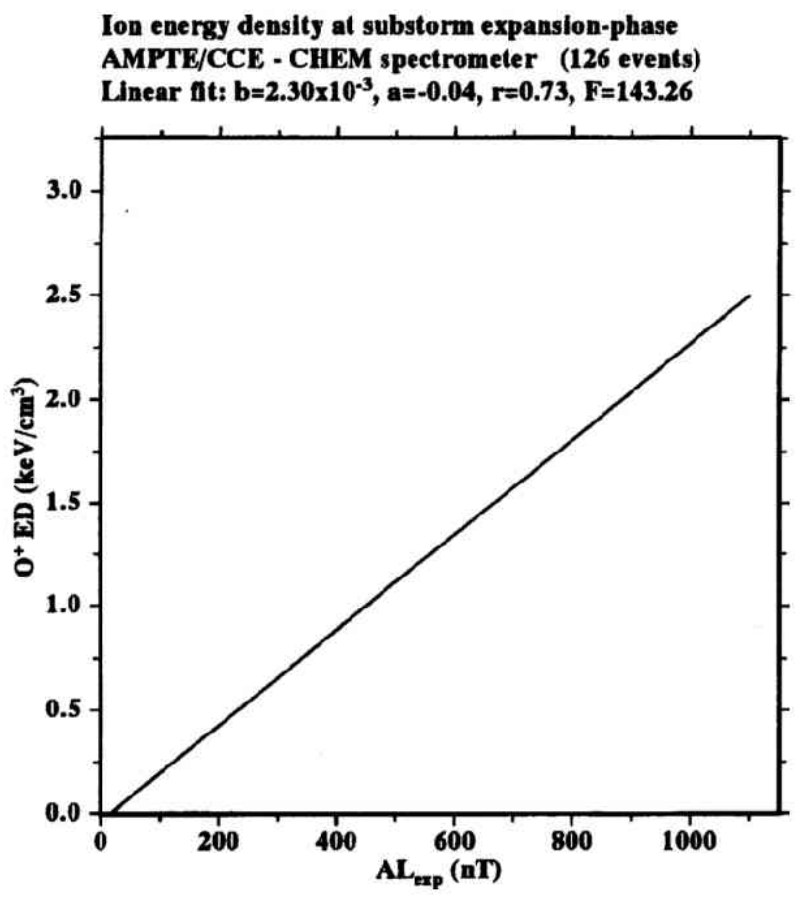

Fig. 1. The diagram demonstrates the strong correlation between the $\mathrm{O}^{+}$energy density and the auroral electrojet intensity during substorm expansion phase on timescales of minutes.

a confidence level higher than $99.99 \%$. The corresponding fit for $\mathrm{He}^{++}$(not shown here) gave $E D\left(\mathrm{He}^{++}\right)=0.29+0.39 \cdot 10^{-3} \cdot A L$, with a correlation coefficient of 0.29 and an $F$-ratio value of 11.09 , showing that the energy density of the solar wind origin $\mathrm{He}^{++}$correlates very poorly with the auroral electrojet intensity, in contrast to the ionospheric-origin $\mathrm{O}^{+}$ions.

The time resolution used by Daglis et al. in these studies was $15 \mathrm{~min}$, which is far better than the time resolution of previous relevant statistical studies. Most of the previous studies had used long-time averages of $A E$ indices or the $K p$ index (e.g. Young et al., 1982; Lennartsson and Sharp, 1985; Lennartsson and Shelley, 1986). However, within a time interval of 3 or more hours, several substorms can take place and both the magnetospheric conditions and the ionospheric state can undergo a series of dramatic changes. The use of several-minute averages of $A E$ data guarantees that the substorm features are not a priori smoothed out (Baker et al., 1986).

Furthermore, the above mentioned studies of AMPTE/CCE observations were the first statistical studies of energy density in the near-Earth magnetotail with multi-species ion data extending into the higher energy range $(\geq 20 \mathrm{keV} / e)$. A large gap in multispecies ion measurements between 20 and $200 \mathrm{keV}$ existed until the middle of the 1980s; this was considered critical in the effort to assess the makeup of magnetospheric populations (Young, 1983). Furthermore, the energy range between 20 and $200 \mathrm{keV}$ was suggested (Williams, 1981) and later shown (Krimigis et al., 1985; Hamilton et al., 1988) to be the most important energy range during the main phase of geomagnetic storms, because the bulk of the ring current energy density is contained within this range. Later, Daglis et al. (1994b) showed that the high-energy range is also the most important range during the substorm expansion phase: they showed that the energy density is essentially carried by the high-energy ( $\geq 20 \mathrm{keV}$ ) ions during substorm expansion (see Fig. 11 of Daglis et al. (1994a)). It is obvious that measurements in the high energy range ( $\geq 20 \mathrm{keV})$ are critical for 


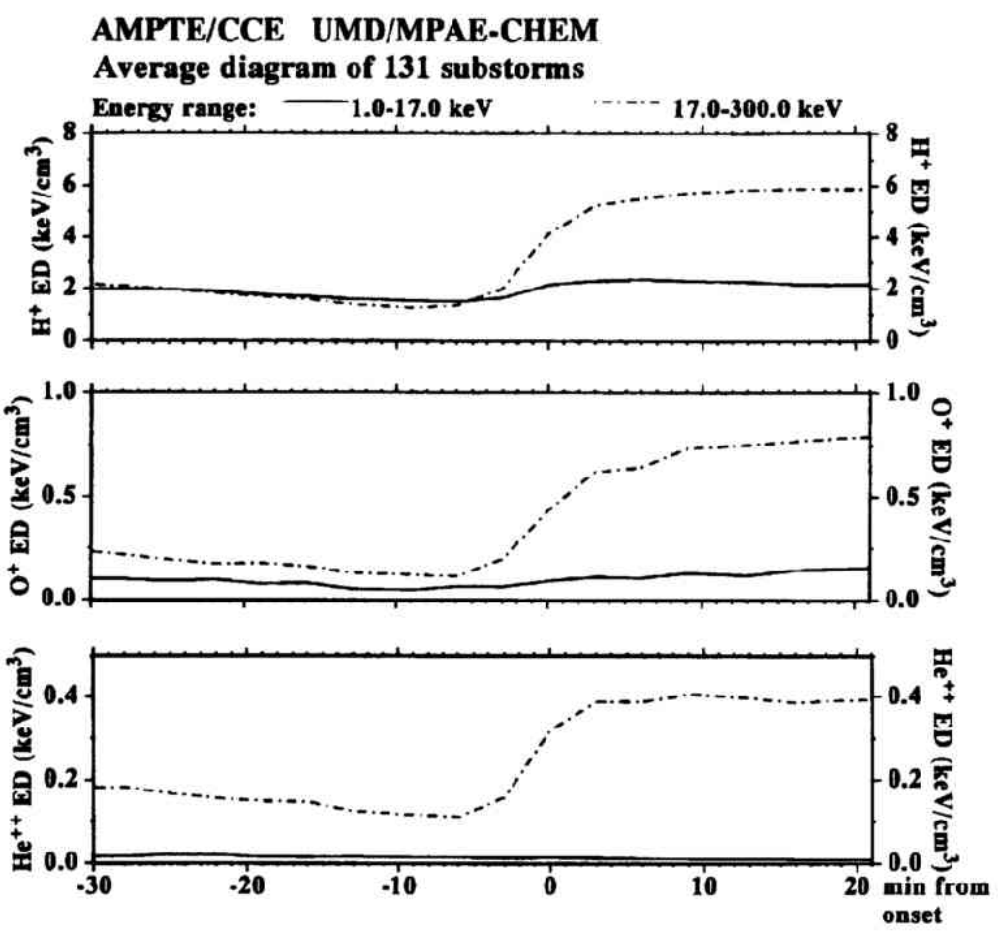

Fig. 2. The diagram shows the time profile of the average energy density gain for 131 substorms observed by AMPTE/CCE in the nightside magnetosphere, near $r / R_{E}=8$ and around local midnight (after Daglis (1991)). The two main features are the continuing increase of $\mathrm{O}^{+}$energy density gain, contrary to $\mathrm{H}^{+}$and $\mathrm{He}^{++}$, and the maximum reached by $\mathrm{O}^{+}$, which is about double the maximum of the other two ion species.

substorm studies.

A remarkable statistical difference between the ionospheric-origin $\mathrm{O}^{+}$and the solar wind origin $\mathrm{He}^{++}$during substorms was presented by Daglis (1991): after the substorm onset the $\mathrm{O}^{+}$ energy density is gradual and continuous while the energy density gain of $\mathrm{He}^{++}$is like a step function, that is it takes place only just after onset. The continuing rise in energy density gain of $\mathrm{O}^{+}$, in contrast with the step-wise gain of $\mathrm{H}^{+}$and $\mathrm{He}^{++}$energy density indicates a source of $\mathrm{O}^{+}$which remains active for some time after the substorm expansion onset. Furthermore, $\mathrm{O}^{+}$ reaches the highest relative energy density gain among the major ion species (Fig. 2).

The CRRES mission followed the AMPTE mission and its orbit configuration made it very suitable to cross-check the AMPTE results. During the 13 months of the mission lifetime, the eccentric orbit of CRRES permitted the exploration of the inner magnetosphere, from the outer radiation belts up to the inner boundary of the plasma sheet, over magnetic local times from 0800 (through 2400) to 1600 hours. The substorm observations that we present here, indicate a fast ionospheric ion feeding of the inner plasma sheet during the substorm expansion. Observations implying direct injection of ionospheric ions into the mid-tail plasma sheet $\left(15 \leq r / R_{E} \leq 30\right)$ were previously presented by Möebius et al. (1987) and Orsini et al. $(1988,1990)$.

\section{Observations}

We shall present substorm observations from the CRRES mission. CRRES was launched on 25 July 1990, and was operational until 9 October 1991; it had an elliptic orbit with geocentric 
apogee at $\sim 6.3 R_{E}$, a perigee altitude of $370 \mathrm{~km}$ and an orbital inclination of $\sim 18.1^{\circ}$. The orbital period was $\sim 10$ hours, and the spin period was approximately $30 \mathrm{~s}$ with the spin axis pointing roughly toward the Sun. A detailed description of CRRES is given by Johnson and Kierein (1992).

For this study we have used particle data from the Magnetospheric Ion Composition Spectrometer (MICS), which belongs to a class of advanced instruments providing full characterization of incident ions by determining their mass $A$, charge $Q$ and velocity $V$ (Wilken et al., 1992). MICS determines the ion identity from a combination of electrostatic deflection, post acceleration (improving the resolution at low particle energies) and time-of-flight and energy measurements. The time-of-flight/energy detector geometry was matched to an electrostatic analyzer of an unusual ogive design to achieve high system sensitivity coupled with a rather narrow collimation angle of $1.1^{\circ}$. The double and triple coincidence technique used by MICS provided inherent immunity to background.

We shall present three substorm events observed by CRRES within the first three months of 1991. We deliberately selected events from this time period, because of the availability of provisional $A E$ indices prepared by Alexander G. Yahnin (Polar Geophysical Institute, Apatity, Russia). The first substorm event was observed on 14 to 15 February 1991, with CRRES located in the premidnight magnetosphere. As already reported by Grande et al. (1992), CRRES observed a multiple ion injection during this event, with the first onset at 2352 UT. A remarkable variation was observed with regard to the relative abundance of the solar wind origin $\mathrm{He}^{++}$and the ionospheric-origin $\mathrm{O}^{+}$ions: in the first injection the $\mathrm{He}^{++}$abundance was higher, while in the second injection the $\mathrm{O}^{+}$proportion increased greatly and surpassed $\mathrm{He}^{++}$. Grande et al. (1992) also reported that the count rate of all ions with a charge greater than two (of predominantly solar wind origin) followed a very similar pattern to that of $\mathrm{He}^{++}$. The ratio of $\mathrm{He}^{++}$to the higher charge state material was shown to remain constant throughout that day.

Our main interest has been to investigate the features of energy density, because they constitute valuable diagnostics of the participation of the different plasma sources in the substorm energization process. We have calculated the energy density for the energy range from 20 to 426 $\mathrm{keV}$ for $\mathrm{H}^{+}$and from 50 to $426 \mathrm{keV}$ for $\mathrm{O}^{+}$. Although the useful energy range of MICS extends from $426 \mathrm{keV} / e$ down to about $1 \mathrm{keV} / e$, due to insufficient calibration data the rates we used could be confidently converted to fluxes for the above mentioned energy ranges only.

We show the time profile of the energy density of the three major ion species $\left(\mathrm{H}^{+}, \mathrm{O}^{+}\right.$, $\mathrm{He}^{++}$), along with the contribution of $\mathrm{H}^{+}$and $\mathrm{O}^{+}$to the total encrgy density, in Fig. 3. What is readily recognizable is the time-shifted increase of $\mathrm{O}^{+}$energy density. It is also evident that $\mathrm{H}^{+}$is the dominant ion species, contributing more than $75 \%$ of the total energy density at all times. After the onset of the substorm however, the contribution of $\mathrm{O}^{+}$rises from zero to above $15 \%$ (panel 5), which is also reflected in the fall of the corresponding $\mathrm{H}^{+}$line (panel 4). These features are consistent with a time-shifted (delayed) feeding of the near-Earth magnetotail with, and subsequent injection to the inner magnetosphere of, ionospheric-origin $\mathrm{O}^{+}$ions as a fast response of the high-latitude ionosphere to the onset of the substorm.

Comparison of the energy density time profile with the $A L$ index time profile (Fig. 3) reveals a most interesting similarity between the $A L$ and the $\mathrm{O}^{+}$patterns. The first drop in $A L$ is concurrent with the enhancement in the energy density of both $\mathrm{O}^{+}$and $\mathrm{He}^{++}$. The second $A L$ drop however, is concurrent with the second enhancement in the $\mathrm{O}^{+}$energy density and the increase of its contribution to the total energy density from $\sim 6 \%$ to $12 \%$. Another most interesting feature is that during the second enhancement of $\mathrm{O}^{+}$, the $A U$ index exhibits a jump from the level of the past 30 minutes, which is equivalent to an enhancement of the convectional DP2 current system, a signature of driven energy dissipation. Hence, in this case we see an isolated, transient increase of $\mathrm{O}^{+}$energy density, at the time of coexistence of DP1 and DP2 systems. The global geomagnetic activity during this event was low to moderate $(D s t=-13 \mathrm{nT}$, 

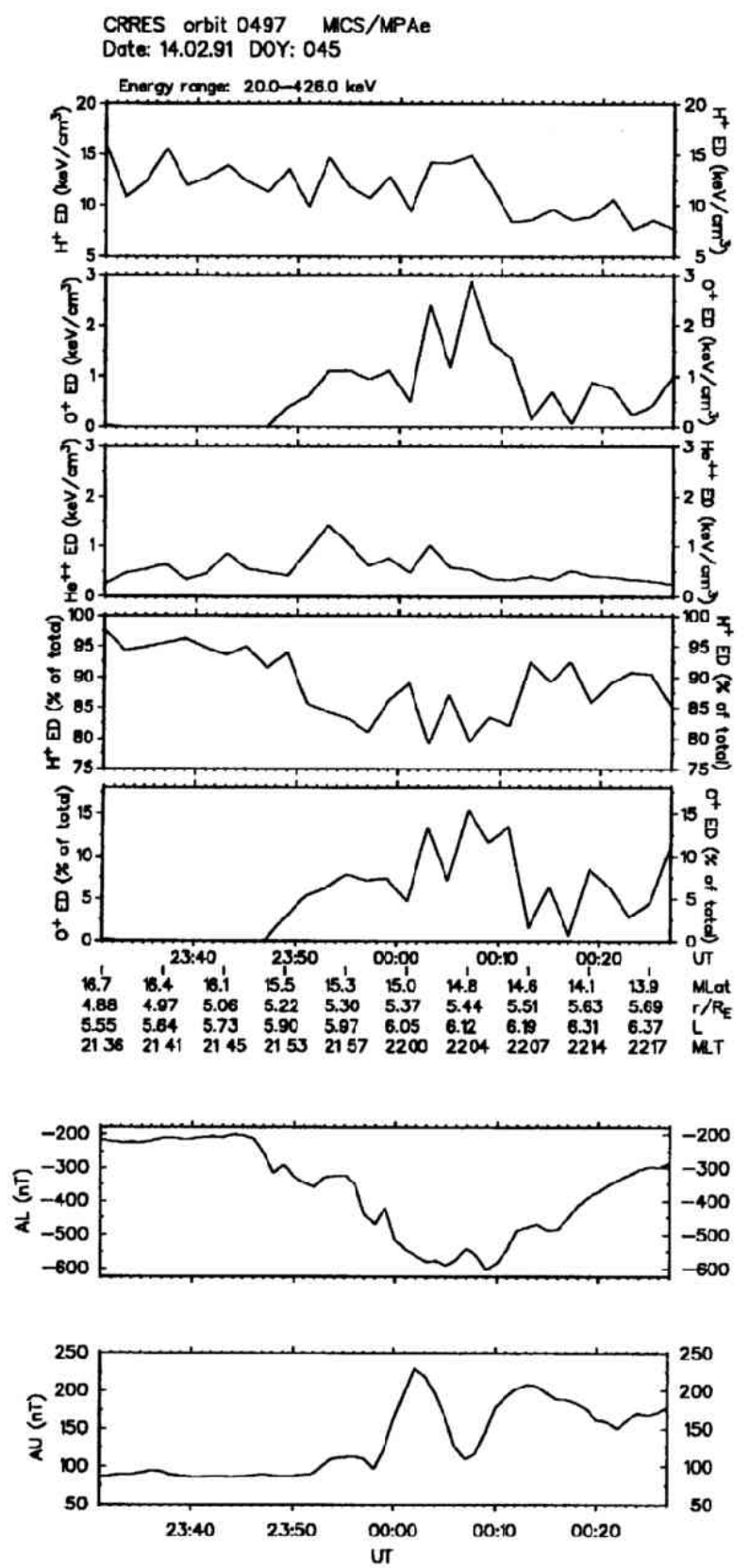

Fig. 3. Energy density time profile and provisional $A E$ indices for the event on 14 February 1991. The seven panels show: 1 . the $\mathrm{H}^{+}$energy density (in $\mathrm{keV} / \mathrm{cm}^{3}$ ), 2. the $\mathrm{O}^{+}$energy density, 3. the $\mathrm{He}^{++}$density, 4. the contribution of $\mathrm{H}^{+}$to the total energy density (in \%), 5. the contribution of $\mathrm{O}^{+}$to the total energy density, 6 . the $A L$ index, 7. the $A U$ index. 

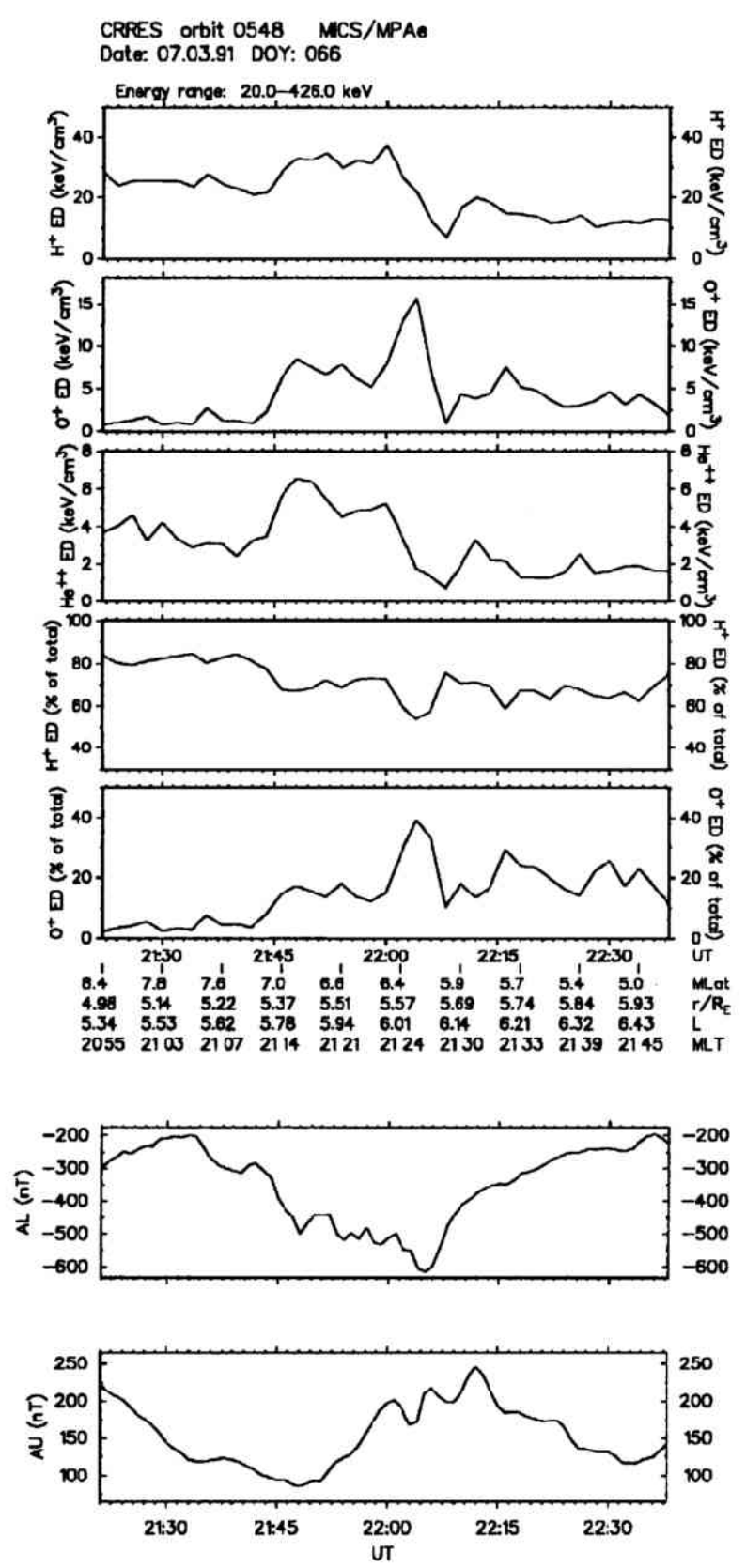

Fig. 4. Energy density time profile and provisional $A E$ indices for the event on 7 March 1991. The format is the same as in Fig. 3.

$K p=3-$ to $4-$ ).

The second substorm event was observed by CRRES on 7 March 1991 . The energy density time profiles and $A E$ indices are shown in Fig. 4, in the same format as in Fig. 3. The local substorm onset was at 2145 UT. One can clearly see the increase of the energy density, which 

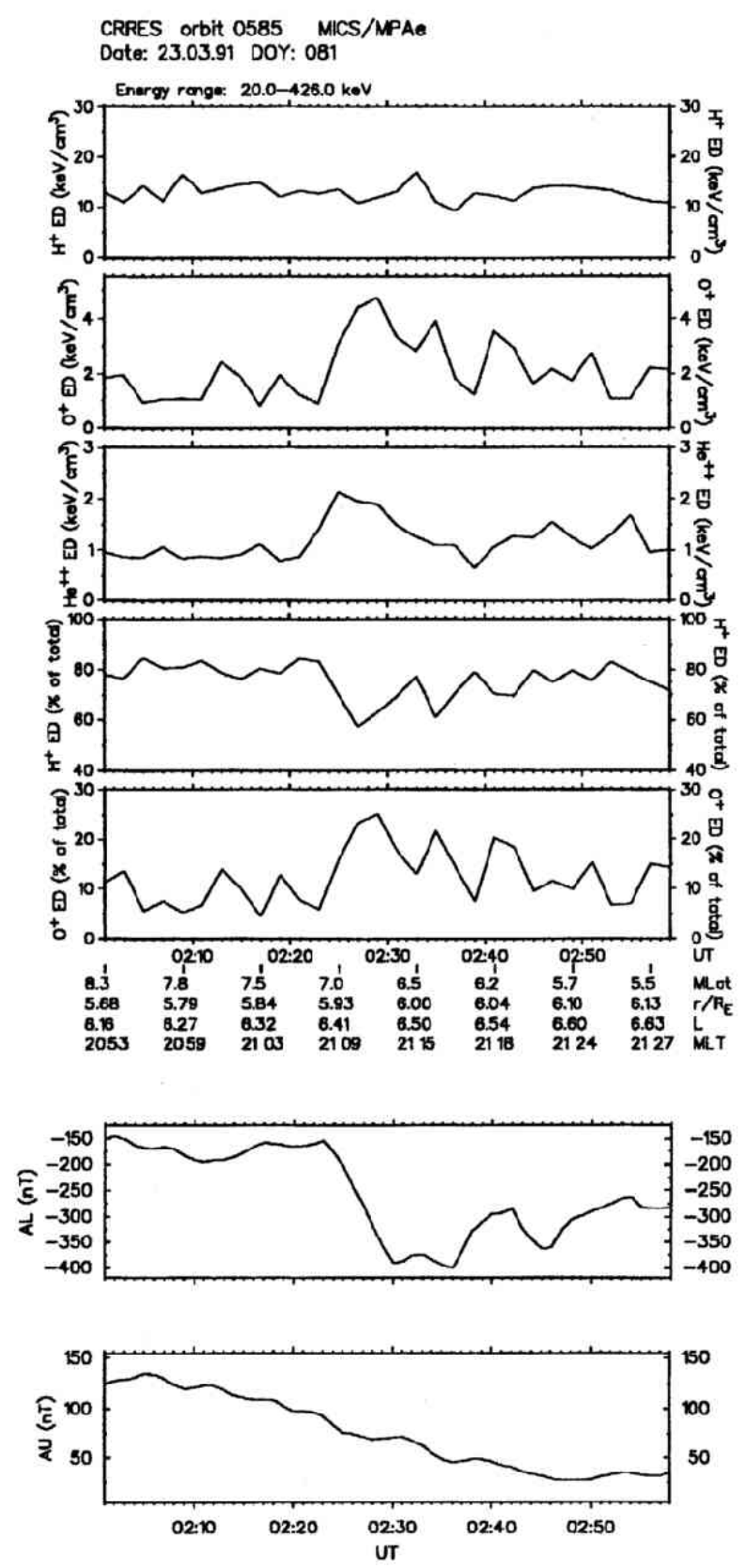

Fig. 5. Energy density time profile and provisional $A E$ indices for the event on 23 March 1991 . The format is the same as in Fig. 3.

is initially common for all three ion species $\left(\mathrm{H}^{+}, \mathrm{O}^{+}, \mathrm{He}^{++}\right)$, and the subsequent intense second enhancement of $\mathrm{O}^{+}$energy density only. Again the $\mathrm{O}^{+}$enhancement is concurrent with a simultaneous increase of both $A L$ and $A U$. The global geomagnetic activity during this event was moderate ( $D s t=-30 \mathrm{nT}, K p=4+$ to $5-$ ). The energy density of all ion species was 
substantially higher in this event, as compared to the event of 14 February 1991 . The energy density of $\mathrm{O}^{+}$in particular, reached rather high values $\left(\sim 15 \mathrm{keV} / \mathrm{cm}^{3}\right)$, contributing about $40 \%$ of the total energy density (panel 5 of Fig. 4).

The third substorm event was observed by CRRES on 23 March 1991 . The onset was at 0222 UT and the energy density time profiles and $A E$ indices are shown in Fig. 5, in the same format as in Fig. 3. The enhancements of energy density in this event are not quite as remarkable as in the previous one. However, one can identify again the striking similarity of the $\mathrm{O}^{+}$and the $A L$ time profiles on a short timescale. During this event however, there has been no increase in the $A U$ magnitude, showing the absence of a combined DP1-DP2 enhanced current system. The global activity in this case was low to moderate ( $D s t=-15, K p: 3-$ to $3+)$.

\section{Discussion}

The substorm events we have presented have a common feature: the $\mathrm{O}^{+}$energy density time profile closely follows the $A L$ index time profile, in contrast with the other two major ion species $\mathrm{H}^{+}$and $\mathrm{He}^{++}$. This is most evident in the concurrent continuing increase of $\mathrm{O}^{+}$ energy density and continuing drop in the $A L$ index. In the two out of the three cases presented here, the extraordinary second rise in $\mathrm{O}^{+}$pressure is concurrent with a combined DP1-DP2 enhanced current system, as shown by the $A L$ and $A U$ indices. Clauer and Kamide (1985) and Kamide and Baumjohann (1985) showed that direct dissipation (DP2 current system) and explosive dissipation (DP1 current system) of energy may coexist during the expansion phase with the direct dissipation being decreased or enhanced as compared to that during the growth phase. Since energy dissipation through ionospheric currents presumably is a critical parameter in the process of ionospheric ion extraction, the relation of direct to explosive energy dissipation may well influence or even determine the morphology of ionospheric ion outflow. However, further research on this issue is needed before conclusions are drawn.

The results of this CRRES case study are very much consistent with the implications of the statistical studies of AMPTE/CCE observations by Daglis et al. (1992) and Daglis et al. (1994b). There is not simply a tendency of higher $\mathrm{O}^{+}$abundance during periods of higher geomagnetic activity (e.g. Young et al., 1982), but rather a concurrent enhancement of the $\mathrm{O}^{+}$energy density and the westward (and, occasionally, the eastward) auroral electrojet. We suggest a fast feeding of the inner plasma sheet with ions of ionospheric origin, initiated by the increased geospace activity and associated magnetosphere reconfigurations ("dipolarizations") after substorm onset (Daglis and Axford, on print, 1996). Although the structure of the near-Earth magnetotail and its connection to the polar ionosphere are still far from clear (Galperin, 1995), it is assumed that the auroral ionosphere is magnetically connected with the inner plasma sheet during substorm expansion, as suggested by Lassen and Friis-Christensen (1991), Galperin and Feldstein (1991) and Jordan et al. (1992). The increased concentration of ionospheric $\mathrm{O}^{+}$ions in the inner plasma sheet may regulate the triggering of successive substorm onsets (e.g., Lakhina, 1995) during periods of continuing solar wind-magnetosphere coupling.

A limitation of the set of events presented here is that all three events were observed by CRRES in the premidnight near-Earth magnetosphere; it has been suggested that this region (rather than the postmidnight region) is more likely to couple with the upper ionosphere during substorms (e.g., Baker et al., 1985).

The outflow of ionospheric ions and their concentration in the plasma sheet is generally transient and localized, as indicated by the studies of Strangeway and Johnson (1983), Heelis et al. (1984) and Stokholm et al. (1985). By "transient" we do not mean that the overall response of the ionosphere to enhanced geospace activity is temporally limited, but rather that different (localized) regions of the upper ionosphere successively respond and feed different parts of the inner magnetotail with outflowing ions for relatively short time intervals (as compared with the duration 
of the substorm expansion). The "intermittent" one-spacecraft observations of the ionospheric outflow and of the ionospheric ion feeding of the inner magnetotail are not sufficient to resolve the spatial/temporal characteristics of magnetosphere-ionosphere coupling during substorms. A useful tool in this context would be energetic neutral atom imaging of the auroral outflow (e.g., Daglis and Livi, 1995) and coordinated composition measurements by more than one spacecraft in the inner magnetotail.

There are obviously various factors influencing the transition from a weak feeding to a strong feeding of the magnetosphere with ionospheric ions, as during great magnetic storms for example (Daglis et al., 1995). Such factors should be the following: the solar UV radiation level influencing the scale height of oxygen in the upper atmosphere, the magnitude of solar wind velocity (Lundin et al., 1995), the auroral current dissipation (Daglis et al., 1994b), the magnitude of induced electric fields during substorm onset dipolarization Daglis et al., 1994a), and certainly the prior history of geomagnetic activity. A future study will investigate the relation between these factors and the ionosphere-magnetosphere coupling through the outflowing ions.

\section{Summary}

We have presented observations of the major ions' energy density by the CRRES satellite during three substorms. We have been interested in energy density variations because they are valuable diagnostics of the participation of the two main sources of magnetospheric plasma in the substorm energization process. There are two conditions that have to be fulfilled for such studies: first is a high time resolution (of the order of several minutes) and second is the information on the high energy range. A high time resolution is crucial, because only a time resolution of the order of several minutes can assure that information on the dynamics of substorm phases will not be masked (Baker et al., 1986). Higher energy range means energies above $20 \mathrm{keV} / e$, which have been shown to be most critical during substorm expansion (Daglis et al., 1994b).

The CRRES-MICS measurements show that the time profiles of $\mathrm{O}^{+}$energy density and $A L$ index are strikingly similar, in contrast to the other major ion species $\mathrm{H}^{+}$and $\mathrm{He}^{++}$. The feature of continuing increase of the $\mathrm{O}^{+}$energy density for some time after substorm onset and after $\mathrm{H}^{+}$and $\mathrm{He}^{++}$have reached their final value, known from statistical studies of AMPTE/CCE observations (Daglis et al., 1994b), is also present in the substorms observed by CRRES. These characteristics suggest a fast response of the ionosphere to increased solar wind-magnetosphere coupling and associated dynamic reconfigurations, in the form of enhanced feeding of the inner plasma sheet by ion outflow from the auroral ionosphere.

The leading author (I.A.D.) acknowledges support by the Deutsche Agentur für Raumfahrtangelegenheiten (German Space Agency) under project 50 OC 95022. The design and fabrication of the CRRES-MICS spectrometer was a joint effort of the Aerospace Corporation (Los Angeles, USA), the Max-Planck-Institut für Aeronomie (Katlenburg-Lindau Germany) as the lead institution, the Rutherford Appleton Laboratory (Didcot, England) and the University of Bergen (Bergen, Norway). Grants were received from the Max-Planck-Gesellschaft zur Förderung der Wissenschaften (Max Planck Society for the Advancement of Sciences), from the United States Air Force under contracts AFOSR 85-0237 and F 04701-88-C-0089, and from the Norwegian Research Council for Science and the Humanities. The $A E$ indices used in this paper were provided by A. G. Yahnin (Polar Geophysical Institute, Apatity, Russia).

\section{REFERENCES}

Baker, D. N., T. A. Fritz, W. Lennartsson, B. Wilken, H. W. Kroehl, and J. Birn, The role of heavy ions in the localization of substorm disturbances on March 22, 1979: CDAW 6, J. Geophys. Res., 90, 1273-1281, 1985. 
Baker, D. N., L. F. Bargatze, and R. D. Zwickl, Magnetospheric response to the IMF: substorms, J. Geomag. Geoelectr., 38, 1047-1073, 1986.

Balsiger, H., P. Eberhardt, J. Geiss, and D. T. Young, Magnetic storm injection of 0.9- to 16-keV/e solar and terrestrial ions into the high-altitude magnetosphere, J. Geophys. Res., 85, 1645-1662, 1980.

Clauer, C. R. and Y. Kamide, DP1 and DP2 current system for the March 22, 1979, substorms, J. Geophys. Res., 90, 1343-1354, 1985.

Daglis, I. A., Study of substorm dynamics in the Earth's magnetosphere with AMPTE/CCE observations, Ph.D. thesis, Demokritos Univ. of Thrace, Xanthi, Greece, 1991.

Dagkusm, U. A. and W. I. Axford, Fast ionospheric response to enhanced activity in geospace: Ion feeding of the inner magnetotail, J. Geophys. Res., 101, 5047-5065, 1996.

Daglis, I. A. and S. Livi, Merits for substorm research from imaging of charge-exchange neutral atoms, Ann. Geophys., 13, 505-516, 1995.

Daglis, I. A., N. P. Paschalidis, E. T. Sarris, W. I. Axford, G. Kremser, B. Wilken, and G. Gloeckler, Statistical features of the substorm expansion-phase as observed by AMPTE/CCE, in Magnetospheric Substorms, Geophys. Monogr. Ser., vol. 64, edited by J. R. Kan, T. A. Potemra, S. Kokubun, and T. Iijima, pp. 323-332, AGU, Washington, D.C., 1991.

Daglis, I. A., E. T. Sarris, G. Kremser, and B. Wilken, On the solar wind-magnetosphere-ionosphere coupling: AMPTE/CCE particle data and the AE indices, Study of the Solar-Terrestrial System, Eur. Space Agency Spec. Publ., SP-346, 193-198, 1992.

Daglis, I. A., M. Banaszkiewicz, and E. B. Wodnicka, Coupling of the high-latitude and the equatorial magnetosphere during substorms through the transport/acceleration of ionospheric ions, in Proc. International Conference on Substorms 2, Fairbanks, U.S.A., March 7-11, edited by J. R. Kan, J. D. Craven, and S.-I. Akasofu, pp. 615-619, Univ. of Alaska, Fairbanks, 1994a.

Daglis, I. A., S. Livi, E. T. Sarris, and B. Wilken, Energy density of ionospheric and solar wind origin ions in the near-Earth magnetotail during substorms, J. Geophys. Res., 99, 5691-5703, 1994b.

Daglis, I. A., W. I. Axford, S. Livi, B. Wilken, and E. T. Sarris, O+ ions in the inner magnetosphere during magnetic storms, Paper presented at the IUGG XXI General Assembly, Boulder, U.S.A., July 2-14, Book of abstracts, p. 254, 1995.

Galperin, Y. I., Magnetospheric tail structure: Concepts, problems and storm-time development of the auroral oval, J. Atmos. Terr. Phys., 57, 1397-1414, 1995.

Galperin, Y. I. and Y. I. Feldstein, Auroral luminosity and its relationship to the magnetospheric plasma domains, in Auroral Physics, edited by C.-L. Meng, M. J. Rycroft, and L. A. Frank, pp. 207-222, Cambridge Univ. Press, New York, 1991.

Gloeckler, G. and D. C. Hamilton, AMPTE ion composition results, Phys. Scr., T18, 73-84, 1987.

Grande, M., C. H. Perry, D. S. Hall, B. Wilken, S. Livi, F. Søraas, and J. F. Fennell, Composition signatures of substorm injections, Substorms 1, Eur. Space Agency Spec. Publ., SP-335, 485-490, 1992.

Hamilton, D. C., G. Gloeckler, F. M. Ipavich, W. Stüdemann, B. Wilken, and G. Kremser, Ring current development during the great geomagnetic storm of February 1986, J. Geophys. Res., 93, 14,343-14,355, 1988.

Heelis, R. A., J. D. Winningham, M. Sugiura, and N. C. Maynard, Particle acceleration parallel and perpendicular to the magnetic field observed by DE-2, J. Geophys. Res., 89, 3893-3902, 1984.

Hultqvist, B., Extraction of ionospheric plasma by magnetospheric processes, J. Atmos. Terr. Phys., 53, 3-15, 1991.

Johnson, M. H. and J. Kierein, Combined Release and Radiation Effects Satellite (CRRES): Spacecraft and Mission, J. of Spacecraft and Rockets, 29, 556-563, 1992.

Jordan, C. E., J. N. Bass, M. S. Gussenhoven, H. J. Singer, and R. V. Hilmer, Comparison of magnetospheric magnetic field models with CRRES observations during the August 26, 1990, storm, J. Geophys. Res., 97, 16,907-16,920, 1992.

Kamide, Y. and W. Baumjohann, Estimation of electric fields and currents from IMS magnetometer data for the CDAW-6 intervals: Implications for substorm dynamics, J. Geophys. Res., 90, 1305-1317, 1985.

Krimigis, S. M., G. Gloeckler, R. W. McEntire, T. A. Potemra, F. L. Scarf, and E. G. Shelley, Magnetic storm of September 1, 1981: a synthesis of ring current spectra and encrgy densities measured with AMPTE/CCE, Geophys. Res. Lett., 12, 329-332, 1985.

Lakhina, G. S., Excitation of plasma sheet instabilities by ionospheric $\mathrm{O}^{+}$ions, Geophys. Res. Lett., 22, 3453-3456, 1995.

Lassen, K. and E. Fris-Christensen, Driven and unloading electrojets during the main phase of a magnetic storm, in Magnetospheric Substorms, Geophys. Monogr. Ser., vol. 64, edited by J. R. Kan, T. A. Potemra, S. Kokubun, and T. Iijima, pp. 399-407, AGU, Wasington, D.C., 1991.

Lennartsson, W. and R. D. Sharp, Relative contributions of terrestrial and solar wind ions in the plasma sheet, Adv. Space Res., 5 (4), 411-414, 1985.

Lennartsson, W. and E. G. Shelley, Survey of $0.1-$ to $16-\mathrm{keV} / e$ plasma sheet ion composition, J. Geophys. Res., 91, 3061-3076, 1986.

Lockwood, M., J. H. Waite Jr., T. E. Moore, J. F. E. Johnson, and C. R. Chappell, A new source of suprathermal 
$\mathrm{O}^{+}$near the dayside polar cap boundary, J. Geophys. Res., 90, 4099-4116, 1985.

Lundin, R., M. Yamauchi, J. Woch, and G. Marklund, Boundary layer polarization and voltage in the 14 MLT region, J. Geophys. Res., 100, 7587-7597, 1995.

Möbius, E., M. Scholer, B. Klecker, D. Hovestadt, G. Gloeckler, and F. M. Ipavich, Acceleration of ions of ionospheric origin in the plasma sheet during substorm activity, in Magnetotail Physics, edited by A. T. Y. Lui, pp. 231-234, Johns Hopkins Univ. Press, Baltimore, Md., 1987.

Orsini, S., M. Candidi, M. Stokholm, and H. Balsiger, Injection of ionospheric ions into the plasma sheet in the Earth's magnetotail, Adv. Space Res., 8 (8), 175-178, 1988.

Orsini, S., M. Candidi, M. Stokholm, and H. Balsiger, Injection of ionospheric ions into the plasma sheet, J. Geophys. Res., 95, 7915-7928, 1990.

Shelley, E. G., R. G. Johnson, and R. D. Sharp, Satellite observations of energetic heavy ions during a geomagnetic storm, J. Geophys. Res., 77, 6104-6110, 1972.

Stokholm, M., E. Amata, H. Balsiger, M. Candidi, S. Orsini, and A. Pedersen, Low energy ( $<130 \mathrm{eV})$ oxygen ions at the geosynchronous orbit during the CDAW 6 event of March 22, 1979, J. Geophys. Res., 90, 1253-1261, 1985 .

Strangeway, R. J. and R. G. Johnson, Mass composition of substorm-related energetic ion dispersion events, J. Geophys. Res., 88, 2057-2064, 1983.

Wilken, B., W. Weiss, D. Hall, M. Grande, F. Søraas, and J. F. Fennell, Magnetospheric Ion Composition Spectrometer onboard the CRRES spacecraft, J. of Spacecraft and Rockets, 29, 585-591,

Williams, D. J., Ring current composition and sources: An update, Planet. Space Sci., 29, 1195-1203, 1981.

Yau, A. W., B. A. Whalen, W. K. Peterson, and E. G. Shelley, Distribution of upflowing ionospheric ions in the high-altitude polar cap and auroral ionosphere, J. Geophys. Res., 89, 5507-5522, 1984.

Young, D. T., Near-equatorial magnetospheric particles from $\sim 1 \mathrm{eV}$ to $\sim 1 \mathrm{MeV}$, U.S. Natl. Rep. Int. Union Geod. Geophys. 1979-1982, Rev. Geophys., 21, 402-418, 1983.

Young, D. T., H. Balsiger, and J. Geiss, Correlations of magnetospheric ion composition with geomagnetic and solar activity, J. Geophys. Res., 87, 9077-9096, 1982. 